\title{
Detección inmunoenzimática de la toxina de la bacteria Clostridium tetani: una alternativa a las pruebas biológicas con ratones
}

\author{
Fernando Chaves ${ }^{1,2 *}$, Guillermo León ${ }^{1,2}$ \& Francisco Hernández-Chavarría ${ }^{1,3 * *}$ \\ Facultad de Microbiología, Universidad de Costa Rica, San José, Costa Rica. \\ Instituto Clodomiro Picado, Universidad de Costa Rica, San José, Costa Rica. \\ Centro de Investigación en Estructuras Microscópicas (CIEMic), Universidad de Costa Rica, San José, Costa Rica. \\ fchaves@icp.ucr.ac.cr \\ ** Correspondencia: CIEMic, Universidad de Costa Rica, San José, Costa Rica; franciscohernandez@ice.co.cr
}

Recibido 13-II-2001. Corregido 02-IV-2002. Aceptado 08-XII-2003.

\begin{abstract}
Immunoenzimatic detection of the Clostridium tetani bacterial toxin: an alternative to mice bioassays. Cell-free extracts from 20 strains of Clostridium tetani isolated from soil samples, were tested for tetanus toxin production using an enzyme immunoassay. All the extracts were classified as positive for the toxin presence, and eight of them showed absorbance values corresponding to tetanus toxin concentrations between 3.2 and $88 \mathrm{ng} / \mathrm{ml}$; thus, they fell within the linear absorbance range (0.135-0.317). All dilutions of toxin used to obtain the calibration curve ( 0.0071 to $1.1 \mathrm{ng}$ ) were lethal for mice. Rev. Biol. Trop. 54(2): 253-256. Epub 2006 Jun 01.
\end{abstract}

Key words: Clostridium tetani, tetanus toxin, enzyme-immunoassay, biological assay.

El género Clostridium está representado por bacilos anaerobios productores de esporas, habitantes normales del suelo e incluye los dos agentes productores de las neurotoxinas naturales más poderosas: $C$. tetani y $C$. botulinum, responsables del tétanos y el botulismo, respectivamente (Hatheway 1990). En el tétanos la puerta de entrada más frecuente al organismo son traumatismos, usualmente asociados con tejidos macerados, en los cuales las esporas de C. tetani provenientes del suelo, germinan y producen la toxina. En el caso del tétanos neonatorum, la puerta de entrada es la herida umbilical contaminada durante un parto debido a técnicas asépticas deficientes y cuando la madre no tiene un buen esquema de vacunación (Dowell 1984, Hernández-Chavarría et al. 2000).

El tétanos se puede prevenir con la vacunación con el toxoide tetánico, lo que ha modificado los patrones epidemiológicos de la enfermedad; en países desarrollados se reduce a casos esporádicos en ancianos (Anónimo
1998), mientras que en países en desarrollo sigue siendo un problema importante a cualquier edad, cuya prevalencia muestra una curva bimodal, debido al tétanos neonatorum y al de ancianos (Whitman et al. 1992). Por esa razón la prevalencia de la enfermedad es mayor en la banda tropical y subtropical del planeta, que aloja a la mayoría de los países en desarrollo (Boerma y Stroh 1993, Bonanni 1999).

Debe aclararse que un buen esquema de vacunación protege a la población, pero no afecta la circulación de la bacteria en la naturaleza, pues es un habitante normal del suelo (Veronesi et al. 1975). Su frecuencia en suelos de diferentes latitudes generalmente es superior al 30\% de las muestras examinadas (Hatheway 1990), lo que en Costa Rica se ha corroborado (Hernández et al. 1997, Hernández y Rodríguez 1993, Hernández-Chavarría et al. 2000, 2001).

Para la identificación de las cepas toxigénicas de $C$. tetani se inocula por triplicado $0.1 \mathrm{ml}$ de un sobrenadante libre de células del 
cultivo sospechoso en ratones jóvenes (con un peso corporal menor de $20 \mathrm{~g}$ ). Los animales se dejan en observación por 24 horas; en el caso de cepas toxigénicas, éstos morirán con un cuadro de tétanos, lo que incluye contracciones tetánicas y en última instancia un fallo respiratorio. Entonces se debe proceder a una prueba confirmatoria, mediante neutralización de la toxina con un suero antitoxina. Los sobrenadantes que indujeron la muerte de los animales, se mezclan con un suero anti tetánico y nuevamente se inoculan en ratones, si éstos sobreviven se confirma la identificación de la toxina (Beland y Rossier 1973). Por lo tanto, en la investigación de las posibles cepas toxigénicas de $C$. tetani se requiere una cantidad importante de ratones, que podría disminuirse si en los esquemas de identificación se incluyera una prueba serológica, ya fuese como diagnóstico definitivo o incluso de tamizaje.

La literatura médica es rica en descripciones de técnicas inmunoenzimáticas diseñadas para detectar anticuerpos anti-tétanos (Alagappan et al. 1996, Shohat et al. 2000). Hasta donde sabemos, esas pruebas no se han utilizado sistemáticamente en la detección de la toxina (antígeno), como método de identificación de C. tetani, lo cual es el objetivo de este trabajo.

Se adaptó una prueba inmunoenzimática para la detección de toxina tetánica (antígeno), siguiendo los lineamientos establecidos para tal metodología (Simhon et al. 1979, Tijseen 1985, Lomonte y Rojas 1996). Brevemente, la prueba consistió en sensibilizar placas de microtítulo de 96 hoyos (Immulon 2, Dynatech Laboratories, EUA) con $100 \mu \mathrm{l}$ de un suero comercial anti tetanospasmina, diluido $1 / 1000$ en solución salina y se incubó por 24 horas/ $4^{\circ} \mathrm{C}$. Las reacciones inespecíficas se bloquearon con una solución de albúmina bovina al $2 \%$, previamente antes de colocar los sobrenadantes de las cepas a evaluar. Éstos se inocularon (100 $\mu \mathrm{l} /$ hoyo $)$ e incubaron a temperatura ambiente por una hora. La reacción se detectó adicionando a cada hoyo una alícuota $(100 \mu \mathrm{l})$ de un suero de conejo anti fragmento $\mathrm{C}$ de la tetanospasmina diluido 1/1000 en solución salina-albúmina bovina y se incubó por una hora a temperatura ambiente. La reacción inmune se evidenció mediante un conjugado de inmunoglobulina de cabra anti inmunoglobulina de conejo marcado con fosfatasa alcalina y se reveló con el sustrato de fosfatasa alcalina.

La prueba se estandarizó evaluando por triplicado una serie de diluciones (1:3) de un patrón de toxina concentrada $(143 \mu \mathrm{g} / \mathrm{ml})$ cuyos valores de absorbancia se graficaron para calcular el coeficiente de correlación (r) e intrapolar los valores de absorbancia que se interpretarían como positivos en el estudio de los sobrenadantes bacterianos. Además, se correlacionó la prueba serológica con la biológica, a partir de una serie de diluciones de tetanospasmina de $7.15 \mu \mathrm{g} / \mathrm{ml}$, hasta $1.1 \mathrm{ng}$, lo que correspondió a una serie de diluciones desde 1:3 hasta 1: 131220.

Empleando la técnica descrita se evaluó un grupo de 20 cepas de Clostridium tetani aisladas de suelo (Hernández et al. 1997, HernándezChavarría et al. 2000). Cada cepa fue inoculada en un tubo de carne glucosa tipo PRAS e incubó por 24 horas a $35^{\circ} \mathrm{C}$; al cabo de ese tiempo, los cultivos se congelaron y descongelaron 5 veces para romper las bacterias y liberar la posible toxina. Cada cultivo se centrífugo (2000 g/20 mint) para obtener un sobrenadante libre de células para la prueba IE. Además, se incluyó como control positivo una cepa de $C$. tetani toxigénica (ATCC 19405), cuyos valores de absorbancia se mantuvieron similares en los diversos días en que se analizaron las muestras.

La prueba IE fue positiva en todas las diluciones del patrón de toxina empleadas para evaluar la prueba y correlacionarla con la prueba biológica. Los valores de absorbancia obtenidos oscilaron entre $0.502 \pm 0.05$ y 0.134 \pm 0.002 . Para efectos prácticos se trazó la curva de mejor tendencia, eliminando las diluciones extremas, lo que mostró una curva con un coeficiente de correlación de $r=0.9979$. Los ratones inoculados con cada una de esas diluciones murieron; en tanto, los ratones control, inoculados con solo el amortiguador empleado como diluente sobrevivieron. Obviamente entre mayor es la concentración de toxina, mayor es el valor de absorbancia detectado. 
Las 20 cepas de C. tetani analizadas mostraron valores de absorbancia en el ámbito considerado como positivo, cuyo valor más alto correspondió a $0.259 \pm 0.002$. Sin embargo, solo 8 de esas están en el ámbito de linealidad de la curva (absorbancia 0.135-0.317), que correspondió a una concentración de toxina entre 3.2 a $88 \mathrm{ng} / \mathrm{ml}$; además, todas produjeron toxicidad en los ratones.

El tétanos es una enfermedad cuyos síntomas son tan característicos que permiten su diagnóstico sin necesidad de aislar la bacteria (Hatheway 1990), el síntoma preponderante son las contracciones musculares muy dolorosas, con dificultad respiratoria, debido a las contracciones de los músculos involucrados con la respiración, que en última instancia llevan a la muerte por fallo respiratorio; además, los espasmos en los músculos faciales producen la mueca conocida como risa sardónica y los espasmos en los músculos de la espalda son de tal magnitud que el paciente se arquea entre los talones y la cabeza, y en todo caso, el dolor extremo es la característica preponderante (LaForce 1969, Schofield 1986, Ernst et al. 1997). Los animales inoculados experimentalmente con la toxina, o sea cuando se confirma que la cepa en cuestión se trata de $C$. tetani, desarrollan un cuadro de tétanos mortal; esto significa, que la prueba biológica conduce al sacrificio de un número importante de animales que mueren sometidos a un estrés intenso, y si el modelo animal se comporta como en humanos, esos animales estarían sufriendo durante su agonía de un dolor extremo.

Por otra parte, desde finales de la década de 1950 se ha promovido la búsqueda de alternativas al empleo masivo de animales en el laboratorio, lo que se resumió en un anagrama de tres R: Reemplazar los animales por pruebas in vitro/ Reducir su número mediante pruebas estadísticas/ Refinar los experimentos para causar el menor sufrimiento posible (Mukerjee 1972). En ese sentido, el empleo de una prueba serológica, como la planteada en este trabajo, permitiría reducir sustancialmente el número de animales empleados en estudios sobre toxigenicidad de clostridios; pues, aceptando esta prueba como un método de tamizaje, permitiría identificar las cepas positivas, lo que obviaría su inoculación en ratones. La prueba biológica entonces se dejaría solo para probar aquellas cepas en las cuales la IE hubiese dado un resultado negativo, ya fuese para confirmar esa negatividad, con lo cual los animales sobrevivirían o bien para captar posibles falsos negativos. De cualquier manera, se reduciría sustancialmente el número de animales inoculados y el sufrimiento de éstos.

\section{AGRADECIMIENTOS}

Al personal del Instituto Clodomiro Picado por el apoyo técnico y a Alberto Alape por suministrar el anticuerpo de conejo antifragmento $\mathrm{C}$ de la tetanospasmina y a Bruno Lomonte por la lectura crítica de este manuscrito y atinadas sugerencias. Este trabajo fue realizado bajo el Proyecto \#430-96-215, de la Vicerrectoría de Investigación de la Universidad de Costa Rica.

\section{REFERENCIAS}

Alagappan, K., W. Rennied, T. Kwiatkowski, J. Falck, F. Silverstone \& R. Silverman. 1996. Seroprevalence of tetanus antibodies among adults older than 65 years. Ann. Emerg. Med. 28: 18-21.

Anónimo. 1998. Neonatal Tetanus-Montana. MMWR Morb. Mortal Wkly. Rep. 47: 928-930.

Beland, S. \& E. Rossier. 1973. Isolement et identification de Clostridium tetani dans le sol des cantons de 1'Est de la province de Quebec. Can. J. Microbiol. 19: 1513-1518.

Boerma, J.T. \& J. Stroh. 1993. Using survey data to assess neonatal tetanus mortality levels and trends in developing countries. Demography 30: 459-475.

Bonanni, P. 1999. Demographic impact of vaccination: A review. Vaccine 17: S120-S125.

Dowell, V.R. Jr. 1984. Botulism and tetanus: selected epidemiologic and microbiologic aspects. Rev. Infec. Dis. 6: S202-S207. 
Ernst, M.E., M.E. Klepser, M. Fouts \& M.N. Marangos. 1997. Tetanus: Pathophysiology and management. Ann. Pharmacother. 31: 1507-1513.

Hatheway C.L. 1990. Toxigenic clostridia. Clin. Microbiol. Rev. 3: 66-98.

Hernández, F. \& E. Rodríguez. 1993. The swarming phenomenon of Clostridium tetani. Rev. Biol. Trop. 41: 857-859.

Hernández, F., E. Rodríguez, M. Umaña \& P. Vargas. 1997. Isolation of swarmer clostridia from soil samples. Rev. Biol. Trop. 45: 1243-1245.

Hernández-Chavarría, F., F. Chaves \& E. Freer. 2000 Clostridium tetani, tétanos y su frecuencia en Costa Rica. Rev. Cost. Cienc. Méd. 21: 191-202.

Hernández-Chavarría, F., F. Chaves \& M. Umaña. 2001. Aislamiento de Clostridium tetani en la ciudad de Puntarenas, Costa Rica y el fenómeno de "swarming”. Rev. Biomed. 12: 80-84.

LaForce, F.M., L.S. Young \& J.V. Bennett. 1969. Tetanus in the United States (1965-1966): Epidemiological and clinical features. N. England. J. Med. 280: 569.

Lomonte V.B. \& G. Rojas. 1996. Manual de laboratorio de inmunología general. Facultad de Microbiología, Universidad de Costa Rica. San José, Costa Rica.
Mukerjee M. 1972. Trends in animal research. Scien. Amer. 215: 70-77.

Schofield, F. 1986. Selective primary health care: Strategies for the control of diseases in the developing world. XXII. Tetanus: A preventable problem. Rev. Infect. Dis. 8: 144-151.

Shohat, T., E. Marva, Y. Sivan, I. Lerman, A. Mates \& A. Cohen. 2000. Immunologic response to a single dose of tetanus toxoid in older people. J. Am. Geriatr. Soc. 48: 949-951.

Simhon, A., S. Amato, F. Hernández, R.H. Yolken \& L. Mata. 1979. Diagnóstico de rotavirus por microscopia electrónica y el ensayo inmunosorbente enzima conjugada (ELISA). Bol. Of. Sanit. Panam. 86: 391-397.

Tijseen, P. 1985. Practice and Theory of Enzyme Immunoassays. Elsevier, Amsterdam, Holanda.

Veronesi, R., H. Cecin, A. Correa, J. Tavares, C. Moraes \& O. J. Bertoldo. 1975. New concepts on tetanus immunization: Naturally acquired immunity. J. Hyg. Epidemiol. Microbiol. Immunol. 19: 126-134.

Whitman C., L. Belgharbi, F. Gasse, C. Torel, V. Mattei \& H. Zoffmann. 1992. Progress towards the global elimination of neonatal tetanus. W. Health Stat. 42: 248-256. 